\title{
Simultaneous Topical Antifungal Skin and Nail Therapy: A Prospective Treatment Option?
}

\author{
Simultane topische Fuß- und Nagelpilztherapie: Eine zukünftige \\ Behandlungsoption?
}

Authors

Institution

\author{
A. Täuber, C. Müller-Goymann
}

Institut für Pharmazeutische Technologie, Technische Universität Braunschweig

\section{Bibliography}

Dol http://dx.doi.org/

10.1055/s-0034-1392775

Published online: 6.8 .2015

Akt Dermatol 2015; 41: 418-424

(c) Georg Thieme Verlag KG

Stuttgart · New York

ISSN 0340-2541

Corresponding author

Prof. Dr. Christel

Müller-Goymann

Technische Universität

Braunschweig

Institut für Pharmazeutische

Technologie

Mendelssohnstraße 1

38106 Braunschweig

C.Mueller-Goymann@tu-bs.de

\section{Abstract \\ $\nabla$}

Superficial fungal infections affect $20-25 \%$ of the world's population with an increasing trend. Common infections are fungal skin and nail diseases (tinea pedis and onychomycosis, respectively), which often occur simultaneously due to autoinoculation. Tinea pedis is mostly provoked by the dermatophyte fungus Trichophyton rubrum, which remains in the outermost skin layer, the stratum corneum (SC). Normally, the treatment is done topically and takes up to four weeks. Just as tinea pedis, about $90 \%$ of onychomycoses is triggered by T. rubrum and Trichophyton mentagrophytes. Toenail onychomycosis is 410 times more common in comparison to fingernails. The nail plate is $0.25-1.0 \mathrm{~mm}$ thick and consists of densely packed keratin cell layers. With a water content of up to $25 \%$ and a lipid content of $0.1-1 \%$, the nail plate is considered

\section{Introduction}

$\nabla$

Fungal skin and/or nail infections (tinea pedis/ onychomycosis) are common diseases, which can lead to severe secondary diseases. According to a survey by [1], $33.8 \%$ of the patients with toenail onychomycosis were likewise suffering from tinea pedis. Therefore, they concluded that effective onychomycosis therapy is an essential requirement to impede spreading of the infection. Topical antifungal therapy is eligible to avoid side effects associated with systemic therapy, to reduce treatment costs and to support patients' compliance [2]. Regarding fungal infections of the toe web and sole part of the feet topical treatment is the therapy of choice [3]. However, for fungal nail infections, topical treatment is only advised for mild to moderate forms without matrix involvement [4]. The nail plate is considered as a hydrophilic gel membrane with an additional lipophilic pathway [5-7]. It is hard and dense and has a as a hydrophilic gel membrane with an additional lipophilic route. Due to its excellent barrier properties and a growth rate of only $2-3 \mathrm{~mm}$ per month, nail mycosis treatment is a remarkable challenge and is often accompanied by high relapse rates. In contrast to the nail plate, SC is considered as an approximately $10 \mu \mathrm{m}$ thick, predominantly lipophilic barrier. Because of the distinct structure of these tissues, hitherto, there are only formulations marketed for either tinea pedis or onychomycosis. A formulation targeting both would therefore be a considerable improvement, but has to fulfil different characteristics. The following review focuses on potential active pharmaceutical ingredients (API) for simultaneous tinea pedis and onychomycosis treatment as well as in vitro models for antifungal efficacy evaluation. It carves out the challenges in simultaneous therapy based on the distinct structure of nail and SC.

thickness of $0.25-1 \mathrm{~mm}$ (depending on the literature) $[2,8,9]$. In contrast to this, the main barrier of the skin, the stratum corneum (SC), is only $10-15 \mu \mathrm{m}$ thick, elastic and represents a lipophilic barrier [10]. Therefore, a formulation targeting both fungal skin and nail infections would be a considerable improvement and benefit for the patient. This approach represents a more convenient therapy, which would increase patients' compliance.

When novel topical formulations are developed, the physicochemical characteristics of the API (e.g. size, charge, $\log \mathrm{P}$ ) as well as the properties of the formulation (e.g. type, $\mathrm{pH}, \mathrm{API}$ concentration, penetration enhancer) have to be considered. Furthermore, interactions of the API and keratin have to be taken into account. After the development of an appropriate formulation, physicochemical characterisation as well as permeation and efficacy experiments have to be performed. Since in vivo studies are expensive 
and of long duration, reliable in vitro models are required for early drug testing experiments and prediction of the antifungal activity [11].

\section{Anatomy and physiology of the nail and skin $\nabla$}

\section{Anatomy of the nail and surrounding tissue}

The human nail apparatus consists of the nail plate, nail bed, nail folds, hyponychium and the nail matrix. The nail matrix, nail bed as well as the surrounding tissue indicate a good blood capillary network. Moreover, the nail bed contains many lymphatic vessels [8]. The nail matrix is responsible for building up the nail plate, which obtrudes via the proximal nail fold and grows $2-3 \mathrm{~mm}$ per month (toenails more slowly than fingernails) $[8,12]$. Due to the slow growth and long turnover times of approximately 160 days for fingernails and 1 year for toenails [8], nail disease treatment is a tedious process. The nail plate's growth varies between individuals and is influenced by age, physical condition (e.g. pregnancy, diseases, malnutrition), gender and climate. The nail plate consists of 80-90 layers of dead, densely packed and highly keratinised cells, the keratinocytes. It is convex-formed, translucent, hard, though a little elastic $[2,8,9]$. A cross section figure indicates that the nail plate can be subdivided into three main layers according to their matrix origin: the dorsal, the intermediate and the ventral with a thickness ratio of $3: 5: 2$ [5]. The ventral layer connects the nail plate with the underlying tissue.

Chemically, the nail plate consists of $\alpha$-keratin, a fibrous scleroprotein. $>90 \%$ of the latter reflects hard, hair-type keratin and the residual soft skin-type keratin. The keratin fibres are linked via cysteine-rich proteins whose disulphide bonds behave like glue and are responsible for the nail plate's strength [8]. The sulphur content of the nail plate mainly originates from these disulphide linkages. Furthermore, small amounts of $\mathrm{N}, \mathrm{Ca}, \mathrm{Mg}$, $\mathrm{Na}, \mathrm{K}, \mathrm{Fe}, \mathrm{Cu}$ and $\mathrm{Zn}$ are present [13]. Under normal conditions, the water content of the nail plate is $18 \%$, but it considerably depends on the relative humidity. Water represents a nail plasticiser and is responsible for the flexibility and elasticity of the nail plate [8]. Jointly responsible for nail's flexibility is the high phospholipid concentration in the dorsal- and intermediate layer. However, the overall lipid content of the nail plate accounts for only $0.1-1 \%[12,14]$.

Regarding the surrounding tissue, $75 \%$ of the nail plate is surrounded by the proximal and lateral nail fold, which give support and represent a protection against exogenous substances. The epidermal structure of the nail folds is comparable to skin. The proximal nail fold may influence the growth direction of the nail plate, contribute in the generation of the nail plate and influences the nail plate morphology during an inflammation [15].

\section{Anatomy of the skin}

The human skin represents not only an efficient barrier to the surroundings, but is likewise important for hydrolytic balance, immunologic, sensoric and excretoric functions and regulation $[16,17]$. It protects the body from water loss and consists of two layers: the dermis and the epidermis. The epidermis itself is composed of five different strata: stratum basale, stratum lucidum, stratum spinosum, stratum granulosum and the uppermost stratum, i.e., the SC. The SC accounts for $>80 \%$ of the transport barrier function $[17,18]$. Beginning from the basal layer, the cells differentiate and move towards the skin surface. Final differentiation takes place at the interface between the stratum granulosum and SC, where the viable cells loose their nuclei. A simplified description of the SC is the brick and mortar model with the corneocytes representing the bricks and being held together by the surrounding lipid matrix, the mortar [17]. The SC is $10-15 \mu \mathrm{m}$ thick and constituted of layers of dead, keratinised, flattened keratinocytes, the corneocytes, which are connected via specialised intercellular protein junctions, the corneodesmosomes [19]. The number of cell layers depends on the anatomical location: SC of the heel contains $86 \pm 36$ cell layers, whereas SC of the genital region only consists of $6 \pm 2$ cell layers [19]. The duration of a complete turnover of SC likewise varies with its location and age, but takes approximately 14 days [20]. The corneocytes are comprised of tightly bundled keratin filaments, which are stabilised via disulphide bonds. Furthermore, the corneocytes are encapsulated with the so-called cornified envelope, which is composed of a $10 \mathrm{~nm}$ thick protein shell and a $5 \mathrm{~nm}$ thick lipid envelope. The protein envelope mainly consists of loricrin (80\%) and involucrin $(2-5 \%)$. The proteins are cross-linked via both disulphide bonds and by $\mathrm{N}^{\varepsilon}$-( $\gamma$-glutamyl) lysine isopeptide bonds, which are formed by $\mathrm{Ca}^{2+}$-dependant transglutaminases [21]. Around the protein shell, there is a covalently bound monomolecular $\omega$-hydroxy-ceramide layer, the lipid envelope $[22,23]$. The lipid envelope itself is surrounded by the lipid matrix of the SC. The lipid matrix is generated from the lamellar bodies in the keratinocytes of the stratum spinosum/stratum granulosum interface and represents approximately $20 \%$ of the SC. The matrix is highly organised as lamellar lipid layers and seals the spaces between the corneocytes. It consists of approximately $50 \%$ ceramides, $10-20 \%$ fatty acids and $25 \%$ cholesterol (all by mass). Furthermore, low contents of cholesterol esters, cholesterol sulphate and glycosylceramides are enclosed. Cholesterol serves as a plasticiser and fluidiser of the SC. However, unlike in classic biological membranes, no phospholipids can be detected in the SC [24]. The lipid matrix and the cornified envelope together build the physical and water loss barrier, which are essential for the skin. Therefore, the SC represents the principal physical barrier to the penetration of exogenous substances and microbes [25].

\section{Superficial fungal infections}

$\nabla$

Fungal infections can be subdivided into systemic/deep and superficial infections. While systemic fungal infections are severe diseases, superficial fungal infections are considered to be mild diseases. Superficial fungal infections belong to the most prevalent infections around the world and affect $20-25 \%$ of the world's population with an increasing trend [26]. The infections are mainly caused by dermatophytes, which produce several keratin-digesting enzymes and which can therefore invade keratinised structures such as skin, nail and hair, respectively [3].

\section{Onychomycosis}

Fungal infections of the nail bed and/or nail plate are called tinea unguium or onychomycosis and are among the most common dermatological disorders [8]. Onychomycosis often occurs simultaneously with tinea pedis, however, it can be a primary infection as well [3]. Toenail onychomycosis is approximately 4 times more frequent in comparison to fingernails. Moreover, the prevalence of onychomycosis increases with age [27]. 90-95\% of fungal nail infections are caused by dermatophytes with T. rubrum being the most common trigger. $5-10 \%$ are provoked by yeasts and non- 
dermatophyte moulds $[28,29]$. Typical clinical symptoms of a fungal nail infection are a thickened, discoloured, crumbled nail plate, which can be partly detached from the nail bed. Depending on the origin of infection, onychomycosis can be subdivided into four categories: distal and lateral subungual onychomycosis being the most common type of onychomycosis [10] (infection begins at hyponychium and distal or lateral nail edge and spreads to the proximal nail bed), superficial white onychomycosis (white chalky patches on the nail plate surface; fungus invades the nail plate directly), proximal subungual onychomycosis (fungus enters via the proximal nail fold and penetrates the nail plate) and total dystrophic onychomycosis, the latter being the endpoint of all categories $[28,30]$. To determine a fungal nail infection, there are several laboratory tests available, e.g. direct microscopic examination with $10 \%$ potassium hydroxide $(\mathrm{KOH}), \mathrm{KOH}$ with dimethyl sulfoxide or $\mathrm{KOH}$ with chlorazol black E, respectively, culture of the fungus on dermatophyte test medium, histopathologic analysis with periodic acid-Schiff (PAS) stain and molecular biology (e.g. polymerase chain reaction) [30,31]. Negative stain such as PAS provides evidence that the sample is free of fungus. However, if fungal cultures can be detected, no information on the viability or the type of the fungus is given [32]. Therefore, culture of the fungus is needed for identification and viability testing.

Onychomycosis therapy may be systemic or topical or a combination thereof. Topical treatment is advised for mild to moderate infections without matrix involvement and when $<50 \%$ of the distal nail surface is concerned. The advantages of a topical regime are only mild local side effects such as redness, itching and burning, especially rare systemic side effects. However, the patient's compliance and the ability of the API to penetrate into and permeate across the nail plate to reach the source of infection are essential criteria. Systemic treatment or a combination therapy is recommended when $>50 \%$ of the nail plate is infected with matrix involvement. Systemic therapy is considerably effective, however, limited by systemic side effects and the potential for hepatotoxicity and drug interactions. Moreover, chemical or mechanical removal of the nail plate display a treatment option [4].

\section{Tinea pedis}

Fungal infections of the outermost skin layer, the SC, are called tinea pedis or athlete's foot. Tinea pedis is a common disease with an increasing incidence from the adolescence age upwards. Mostly, the lateral toe web and subdigital crevice of the feet are concerned with typical symptoms of tenderness, peeling of the skin itching and foul odour. The main causing agents are dermatophytes, especially T. rubrum. Predisposing factors are skin trauma, tight shoes and macerated skin due to a warm and humid environment. Tinea pedis treatment is done typically topically with e.g. terbinafine, clotrimazole, miconazole, econazole or ketoconazole [3].

\section{API for antifungal nail and skin application}

$\nabla$

Hitherto, there is no commercial formulation available targeting fungal skin and nail infections simultaneously. However, several API are utilised in different concentrations and formulations for tinea pedis and onychomycosis treatment. Therefore, a formulation, which targets both, might be a realisable improvement in topical antifungal therapy.

\section{Amorolfine}

Amorolfine belongs to the morpholine derivates and acts against dermatophytes, yeasts and moulds by inhibiting $\Delta 14$-reductase and $\Delta 7-8$ isomerase in the ergosterol synthesis. It exhibits fungistatic activity [33]. In the USA, it is not approved for onychomycosis therapy. In Europe, a 5\% amorolfine containing nail lacquer is commercially available. The lacquer has to be applied once to twice weekly [30]. Furthermore, an amorolfine hydrochloride containing cream against dermatomycoses is marketed. [34] evaluated the efficacy of a $2 \%$ amorolfine containing nail lacquer versus a $5 \%$ amorolfine containing lacquer in a doubleblind randomised trial. The lacquers were applied once weekly for up to 6 months. Comparing the mycological cure rates after 6 months, the $5 \%$ amorolfine containing lacquer was superior to $2 \%$ lacquer ( $38 \%$ versus $12 \%$ ). [35] compared the efficacy of $5 \%$ amorolfine lacquer applied once versus twice weekly for a 6 months treatment period. 3 months after cessation of the treatment the mycological cure rate in the once weekly group was only slightly, but not significantly lower (45.6\%) in comparison to the twice-weekly group (51.8\%).

\section{Ciclopirox}

Ciclopirox (log P 2.15 http://www.drugbank.ca/drugs/DB01188) is a topical antifungal API of the hydroxypyridone class. It has a broad efficacy spectrum and acts against all clinical relevant dermatophytes, yeasts and non-dermatophyte moulds. Its mechanism of action is not based on interfering in the ergosterol biosynthesis. In lieu thereof, it inhibits metal dependant enzymes due to its high affinity to polyvalent metal cations. Depending on the contact time with the organism and the concentration, ciclopirox may either act fungistatic or fungicidal. Furthermore, it acts antibacterial against Gram-positive and Gram-negative bacteria and indicates anti-inflammatory activity [36,37].

Marketed formulations against tinea pedis are creams or solutions containing $1 \%$ ciclopirox olamine. $1 \%$ ciclopirox olamine represents $0.77 \%$ of the free acid. The olamine entity does not have any pharmacological impact [38]. For onychomycosis treatment, nail lacquers containing $8 \%$ ciclopirox are available. The nail lacquers may be subdivided into a water-soluble lacquer containing hydroxyl propyl chitosan as film-forming agent and a waterresistant lacquer with monoester resin [39].

[37] evaluated the efficacy of a $0.77 \%$ ciclopirox containing gel in the treatment of tinea pedis interdigitalis with secondary bacterial infection. They performed an 8-week double blind, randomised, placebo-controlled study with 100 patients. The application of the gel was once daily and twice daily, respectively, and the application of the vehicle was twice daily. Both treatment regimens with ciclopirox gel received higher treatment scores than the vehicle. Moreover, the treatments did not differ significantly from each other.

[40] did an open non-comparative study with ciclopirox nail lacquer. 40 patients with distal and lateral subungual toenail onychomycosis and patients with lateral subungual toenail onychomycosis were treated once daily for 9 months. The treatment effort was checked after 0, 3, 6 and 9 months by analysing the clinical nail status, $\mathrm{KOH}$ examination and mycological culture. After 9 months, 36\% of the patients showed marked improvement to complete cure.

[41] investigated the efficacy of P-3051, a water-soluble hydrolacquer containing $8 \%$ ciclopirox as API, versus a polyvinyl resin ciclopirox lacquer in a 48 -week trial. $12.7 \%$ of the patients showed 
complete cure. Regarding the placebo group, only $1 \%$ of the patients reached complete cure.

Currently, poloxamer 407-based formulations with ciclopirox olamine have been investigated by [42] for simultaneous antifungal skin and nail therapy. The poloxamer 407-based formulations consisted of poloxamer 407 (P407), isopropyl alcohol (IPA), medium chain triglycerides (MCT), propylene glycol (PG) and double distilled water in given ratios. These 5-component systems were illustrated in a pseudo ternary phase diagram with a fixed 4:1 ratio of P407 and MCT and a fixed 1:1 ratio of IPA/PG. Variation in composition led to formulations with different macroscopical appearances (semi-solid to liquid) as well as different characteristics. The formulations were given codes reflecting their quantitative composition e.g. 1P1070 represented a formulation loaded with $1 \%$ API, while the vehicle itself consisted of $10 \%$ P407 and MCT (4:1), 70\% IPA/PG (1:1) and 20\% double distilled water (all $\mathrm{w} / \mathrm{w}$ ).

In vitro permeation studies with modified Franz diffusion cells were preformed with semi-solid to liquid P407-based formulations. As permeation barriers bovine hoof plates and keratin films (KF) were utilised as artificial nail models as well as SC as skin model. Since SC represents a lipophilic partition membrane and the nail plate is described as a hydrophilic gel membrane with an additional lipophilic pathway, a formulation targeting both has to fulfil different characteristics. Across KF and bovine hoof plates, a formulation with a high water content was beneficial, since water evoked a swelling of the nail plate. Consequently, a greater porosity and more microporous channels occurred leading to a higher permeation of the API. Across SC, incorporation of skin penetration enhancer such as IPA, PG or MCT, respectively, resulted in higher permeated API amounts. Across KF, formulations with $10 \% \mathrm{P} 407 / \mathrm{MCT}$ and $\geq 60 \%$ water showed the highest permeation coefficients. All the other tested P407-based formulations indicated permeation coefficients in the same range, but higher than that of a marketed reference. Across SC, formulations with high IPA/PG content such as 1P1050 and 1P1050_21, containing a $2: 1$ ratio of IPA/PG, indicated high permeation coefficients. Therefore, 1P1050 for instance, represented a P407-based formulation with promising characteristics for a simultaneous antifungal skin and nail therapy.

\section{Luliconazole}

Luliconazole is a broad-spectrum antifungal, which belongs to the imidazole group $[43,44]$. It indicates fungicidal activity by inhibiting $14 \alpha$-demethylase in the ergosterol biosynthesis as well as fungistatic activity by inhibition of extracellular protease secretion. In Japan, it is used as $1 \%$ solution, $1 \%$ cream and $1 \%$ ointment for topical dermatomycosis treatment. In the USA, $1 \%$ luliconazole cream is approved for interdigital tinea pedis therapy and a $10 \%$ luliconazole formulation is being developed for distal subungual onychomycosis. In contrast to other azol derivates, luliconazole has only low binding affinity for keratin [45]. Therefore, it does not suffer a potency reduction in the presence of keratin and would be appropriate for simultaneous antifungal therapy.

The patent application claims luliconazole as API for tinea pedis and onychomycosis treatment. [44] investigated $0.02 \%-1 \%$ luliconazole containing creams in a guinea pig model. The efficacy of $0.1 \%$ luliconazole cream was comparable to $1 \%$ bifonazole cream. Complete cure was achieved with creams containing $\geq 0.05 \%$ luliconazole. In a clinical onychomycosis trial, $10 \%$ luliconazole solution was applied daily for 29 days on 24 patients.
After 7 days, the median nail concentration of luliconazole was considerably higher than the MIC 90 values of T. rubrum and $T$. mentagrophytes [45].

\section{Terbinafine}

Terbinafine is a lipophilic, broad-spectrum antifungal drug (log P $5.51 \mathrm{http} / /$ www.drugbank.ca/drugs/DB00857) and belongs to the allylamine derivates. It acts fungicidal against dermatophytes and yeasts by selectively inhibiting the squalene epoxidase [30]. Terbinafine is approved for topical and systemic antifungal treatment [46]. Several topical creams containing $1 \%$ terbinafine hydrochloride are marketed for tinea pedis therapy. For onychomycosis treatment, the research of a formulation is still ongoing. [47] developed a topical terbinafine nail solution (TNS). Clinical trials of TNS versus vehicle showed higher mycological cure rates and clinical effectiveness for TNS. Mycological cure of TNS was equal in comparison with a $5 \%$ amorolfine lacquer. Moreover, Transfersomes ${ }^{\circledR}$ with $1.5 \%$ terbinafine have been developed for drug delivery to the nail, nail bed and surrounding tissue. [48] evaluated the safety and efficacy of these Transfersomes ${ }^{\circledR}$. The patients were treated twice daily for 12 weeks in a 48 -week study. Mycological cure was documented for $90 \%$ of the samples at week $14,80 \%$ at week 24 and $38 \%$ at week 48 . It is obvious that mycological cure decreased after cessation of the therapy. However, the mycological cure rates are promising, since they are higher in comparison with approved topical therapies.

\section{Permeation studies and efficacy evaluation $\nabla$}

The efficacy evaluation is an essential aspect during the development of novel antimycotic formulations. In vitro permeation studies with vertical diffusion cells across a model membrane are a standard method to analyse the permeated API amount. However, the obtained results of the permeation experiments may differ from the efficacy in vivo. Due to the low availability of human nails and their convex shape, in vitro models using human nail clippings, bovine or equine hoof plates as well as keratin films have been developed.

\section{Permeation studies with vertical diffusion cells}

Permeation experiments with vertical diffusion cells (VDC), e.g. Franz diffusion cells, are a fast and simple method for measuring drug release and permeation from novel formulations. The experiment is usually carried out at $32 \pm 1{ }^{\circ} \mathrm{C}$ with stirring speeds of $600-800 \mathrm{rpm}$. The VDC consist of two compartments, the donor chamber and the receptor chamber, which are held together by a clamp. The donor chamber contains the formulation, whereas the receptor chamber is filled with an appropriate degassed, preheated buffer. Between the two chambers, the permeation membrane is mounted. The VDC is typically made of borosilicate glass, however, other inert materials can be used as well [49]. Sampling should be done in defined time intervals and an appropriate analytical method should be used for quantification of the permeated drug amount. The removed sample volume has to be immediately replaced by freshly preheated buffer.

\section{In vitro efficacy evaluation}

Infected human nail by [50]

In this in vitro model, a nail plate is placed in a Sabouraud dextrose agar, which has been pre-inoculated with a T. mentagrophytes conidial suspension. An O-ring is attached with silicon bond 
on the dorsal surface of the nail. This assembly is incubated for 5 days at $28^{\circ} \mathrm{C}$. Then, $5 \mu \mathrm{L}$ of a formulation are applied into the O-ring and further incubation is done for 14 days at $28^{\circ} \mathrm{C}$. The positive control without treatment shows fungal colonies over the entire nail. In the treated group, the fungal cultures disappear to a certain extent depending on the antifungal efficacy of the formulation. The area of the fungal culture is then determined with NIH image ver. 1.62 software. Following, the nail is removed from the agar and a sample is collected from the ventral side. This sample is further incubated on Sabouraud dextrose agar at $28^{\circ} \mathrm{C}$ for 14 days. This examination is used as a reference, because the sample amounts are not evaluated quantitatively.

\section{Infected nail plate model by [51]}

In order to evaluate the efficacy of antifungal formulations in vitro, [51] developed an infected nail plate model. In this in vitro model, keratin films and bovine hoof plates are used as artificial nail plate models. In brief, a potato glucose agar is inoculated with $7 \mathrm{~d}$ old $T$. rubrum by streaking a cotton swab in three directions over the agar plate. Following, the plate is allowed to dry for 15 min before approximately 5 nail plate models are placed in it. The agar is incubated for 7 days at $30^{\circ} \mathrm{C}$ to enable full colonisation. After 7 days, the infected nail plate models are transferred to a Sabouraud dextrose agar (one model per agar) and a small polyamide ring is glued with silicone paste onto it. Then, the formulation is injected into the polyamide ring by using a sterile syringe and a PET-foil is glued onto the polyamide ring to prevent evaporation of volatile compounds. This assembly is further incubated for 6 days at $30^{\circ} \mathrm{C}$. After 6 days, the fungal growth is evaluated with a score from $0-10$, where 0 represents no fungal growth and 10 denotes full fungal growth. Each batch of 5 nail plate models on one potato glucose agar includes one positive control without treatment, which indicates full fungal growth. This infected nail plate model represents a fast method for efficacy evaluation of novel formulations. After 20 days, the efficacy score of a formulation can already be determined. Moreover, the test can be performed easily and with low costs. Care must be taken that the polyamide ring is glued tightly onto the infected membrane to prevent leakage of liquid formulations.

\section{In vitro onychomycosis model by [11]}

[11] developed an in vitro model to predict the antifungal efficacy of novel antifungal API using bovine hoof plates (thickness: $600 \mu \mathrm{m}$ ) as artificial nail model. For efficacy testing, a hoof plate is mounted in a polypropylene screw vial cap and a rubber ring is fixed on the surface of the hoof plate for tight attachment. Following, the trimmed top of a vial is screwed on the cap to create a reservoir for the formulation. This assembly is then placed in a Sabouraud dextrose agar and $50 \mu \mathrm{L}$ of a formulation are applied and renewed daily on 7 consecutive days. Following, this assembly is transferred to an inoculated Sabouraud dextrose agar and the test solutions are applied daily on 7 further days. 7 days after inoculation, the zone of inhibition is determined in relation to the growth area of the vehicle by using Image 1.48 software. This model presents a fast, cheap and reliable method for efficacy evaluation of antifungal drugs. It indicates corresponding results with the antifungal susceptibility assay and the Franz diffusion test.

\section{TurChub ${ }^{\circledR}$ assay}

The TurChub ${ }^{\circledR}$ assembly created by MedPharm Ltd (Guildford, United Kingdom) is a combination of a permeation study and an efficacy evaluation. It consists of a modified Franz diffusion cell whose receiver compartment is filled with a defined volume of infected agar (e.g. with T. rubrum). An excised tissue is fixed above the agar and on the surface of the tissue the formulation is applied. This assembly is then incubated for a set period of time and at a set temperature. The API has to permeate across the tissue and, depending on its efficacy, has to inhibit fungal growth. The growth inhibition can be detected as an arising zone of inhibition. This model is told to be appropriate for preliminary studies. Moreover, no analytical method (e.g. high performance liquid chromatography (HPLC)) is required (http://www.medpharm.co.uk/formulation-design/ex-vivo-skin-models/).

\section{Infected nail model (TCCT ${ }^{\mathrm{TM}}$ ) by Medpharm Ltd. [10]}

In this model, sterilised human cadaver nails are used. To measure the efficacy of a formulation, ATP levels are used as a biological marker. The bottom sides of the nails are inoculated with a cell suspension of the dermatophyte fungus T. rubrum and then the nails are incubated under set conditions to induce fungal growth. Following, a formulation is applied onto the infected nails' surface and further incubation is done. After three weeks, the nails are removed from the ChubTur ${ }^{\circledR}$ cells and a bioluminescence ATP assay is used to determine the presence of viable T. rubrum cultures. The lower the ATP content, the more efficient the formulation [10]. The advantage of this in vitro model is that full thickness human nail plates are used. Therefore, the assembly is close to the in vivo situation.

\section{Conclusion \\ $\nabla$}

Due to the distinct structure of nail and SC, a simultaneous antifungal skin and nail therapy is a huge challenge. Hitherto, there is no commercial formulation targeting both available. Several API such as ciclopirox, amorolfine, terbinafine and luliconazole are available in different formulations for skin and nail mycosis treatment. A simultaneous formulation might be available in the future, since this represents a convenient approach for the patient and would therefore increase patients' compliance.

\section{Conflict of Interest \\ $\nabla$}

The authors declare no conflict of interest.

\section{Zusammenfassung}

\section{Simultane topische Fuß- und Nagelpilztherapie: Eine zukünftige Behandlungsoption?}

$\nabla$

Oberflächliche Pilzinfektionen betreffen $20-25 \%$ der Weltbevölkerung mit steigender Tendenz. Häufige Infektionen sind Haut- und Nagelpilzerkrankungen (Tinea pedis bzw. Onychomykose), die wegen Autoinokulation oft gleichzeitig auftreten. Tinea pedis wird meist durch den Dermatophyten Trichophyton rubrum ausgelöst, der in der obersten Hautschicht verbleibt, dem Stratum corneum (SC). Üblich ist eine bis zu vier Wochen dauernde topische Behandlung. Genauso wie Tinea pedis werden etwa 90\% der Onychomykosen durch T. rubrum und Tricho- 
phyton mentagrophytes ausgelöst. Onychomykose der Zehennägel ist dabei 4-10-mal häufiger als die der Fingernägel. Die Nagelplatte ist $0,25-1,0 \mathrm{~mm}$ dick und besteht aus dicht gepackten Keratin-Zellschichten. Mit einem Wassergehalt von bis zu 25\% und einem Lipidgehalt von 0,1 bis $1 \%$ wird sie als hydrophile Gelmembran mit einer zusätzlichen lipophilen Route angesehen. Wegen ihrer hervorragenden Barriereeigenschaften und einer Wachstumsrate von nur $2-3 \mathrm{~mm}$ pro Monat stellt die Behandlung von Nagelpilz eine besondere Herausforderung dar und wird oft von Rückfällen begleitet. Im Unterschied zur Nagelplatte wird das SC als etwa $10 \mu \mathrm{m}$ dicke, überwiegend lipophile Barriere betrachtet. Wegen der unterschiedlichen Struktur der Gewebe werden bisher Formulierungen entweder gegen Tinea pedis oder Onychomykose vermarktet. Eine Formulierung, die beides bekämpft, wäre daher eine beträchtliche Verbesserung. Allerdings muss diese verschiedene Eigenschaften erfüllen.

Der obige Beitrag konzentriert sich auf potenzielle pharmazeutische Wirkstoffe für die simultane Tinea pedis- und Onychomykose-Behandlung sowie In-vitro-Modelle für die Bewertung der antimykotischen Wirksamkeit. Es werden die Herausforderungen einer Simultantherapie auf der Grundlage der unterschiedlichen Strukturen des Nagels und des SC herausgearbeitet.

\section{References}

1 Szepietowski JC, Reich A, Garlowska E et al. Factors Influencing Coexistence of Toenail Onychomycosis With Tinea Pedis and Other Dermatomycoses: A survey of 2761 Patients. Arch Dermatol 2006; 142: 12791284

2 Murdan S. Enhancing the nail permeability of topically applied drugs. Expert Opin Drug Deliv 2008; 5: 1267-1282

3 Branscomb R. The Dermatophytoses. Laboratory Medicine 2005; 36: 496-500

4 Lecha M, Effendy I, Feuilhade de Chauvin M et al. Treatment options development of consensus guidelines. J Eur Acad Dermatol Venerol 2005; 19: 25-33

5 Kobayashi $Y$, Miyamoto $M$, Sugibayashi $K$ et al. Drug permeation through the three layers of the human nail plate. J Pharm Pharmacol 1999; 51: $271-278$

6 Mertin D, Lippold B. In-vitro Permeability of the Human Nail and of a Keratin Membrane from Bovine Hooves: Influence of the Partition Coefficient Octanol/Water and the Water Solubility of Drugs on their Permeability and Maximum Flux. J Pharm Pharmacol 1997; 49: 30 - 34

7 Walters KA, Flynn G, Marvel J. Physicochemical characterization of the human nail: permeation pattern for water and the homologous alcohols and differences with the respect to the human stratum corneum. J Pharm Pharmacol 1983; 35: 28 - 33

8 Gupchup G, Zatz J. Structural characteristics and permeability properties of the human nail: A review. J Cosmet Sci 1999; 50: 363-385

9 Saner MV, Kulkarni AD, Pardeshi CV. Insights into drug delivery across the nail plate barrier. J Drug Target 2014; 22: 769 - 789

10 Traynor MJ, Turner RB, Evans CRG et al. Effect of a novel penetration enhancer on the ungual permeation of two antifungal agents. J Pharm Pharmacol 2010; 62: 730-737

11 Sleven $R$, Lanckacker E, Boulet $G$ et al. Development of a novel in vitro onychomycosis model for the evaluation of topical antifungal activity. J Microbiol Meth 2015; 112: 73 - 75

12 Walters KA, Abdalghafor HM, Lane ME. The human nail - Barrier characterisation and permeation enhancement. Int J Pharm 2012; 435: $10-21$

13 Vellar O. Composition of human nail substance. Am J Clin Nutr 1970; 23: $1272-1274$

14 Brown M, Khengar R, Turner R et al. Overcoming the nail barrier: A systematic investigation of ungual chemical penetration enhancement. Int J Pharm 2009; 370: 61-67

15 de Berker D, André J, Baran R. Nail biology and nail science. Int J Cosm Sci 2007; 29: $241-275$
16 Harding $C R$. The stratum corneum: structure and function in health and disease. Dermatol Ther 2004; 17: 6-15

17 Wickett RR, Visscher MO. Structure and function of the epidermal barrier. Am J Infect Control 2006; 34: S98

18 Dubey V, Mishra D, Nahar $M$ et al. Vesicles as tools for the modulation of skin permeability. Expert Opin Drug Deliv 2007; 4: 579-593

19 Ya-Xian Z, Suetake T, Tagami $H$. Number of cell layers of the stratum corneum in normal skin - relationship to the anatomical location on the body, age, sex and physical parameters. Ar Dermatol Res 1999; 291: $555-559$

20 Reddy M, Guy R, Bunge A. Does Epidermal Turnover Reduce Percutaneous Penetration? Pharm Res 2000; 17: 1414-1419

21 Nemes Z, Steinert PM. Bricks and mortar of the epidermal barrier. Exp Mol Med 1999; 31: 5-19

22 Proksch E, Brandner JM, Jensen J. The skin: an indispensable barrier. Exp Dermatol 2008; 17: 1063-1072

23 Kalinin AE, Kajava AV, Steinert PM. Epithelial barrier function: assembly and structural features of the cornified cell envelope. Bioessays 2002; 24: 789-800

24 Wertz PW, van den Bergh B. The physical, chemical and functional properties of lipids in the skin and other biological barriers. Chem Phys Lipids 1998; 91: 85-96

25 Madison K. Barrier Function of the Skin: "La raison d' Être" of the Epidermis. J Invest Dermatol 2003; 121: 231-241

26 Havlickova B, Czaika V, Friedrich $M$. Epidemiological trends in skin mycoses worldwide. Mycoses 2008; 51: 2-15

27 Roberts $D$. Onychomycosis: current treatment and future challenges. Brit J Dermatol 1999; 141: 1-4

28 Murdan S. Drug delivery to the nail following topical application. Int J Pharm 2002; 236: 1 - 26

29 Sigurgeirsson B, Baran $R$. The prevalence of onychomycosis in the global population - A literature study. J Eur Acad Dermatol Venereol 2014; $28: 1480-1491$

30 Finch J, Warshaw E. Toenail onychomycosis: current and future treatment options. Dermatol Ther 2007; 20: 31 - 46

31 Shemer A, Gupta A, Farhi R et al. When is onychomycosis onychomycosis? A cross-sectional study of fungi in normal-appearing nails. Brit J Dermatol 2015; 172: 380-383

32 U.S. Department of Health and Human Services. Medical Devices and Clinical Trial Design for the Treatment or Improvement in the Appearance of Fungally-Infected Nails. Draft Guideline for Industry and Food Drug Administration Staff 2015

33 Tabara K, Szewczyk AE, Bienias $W$ et al. Amorolfine vs. ciclopirox lacquers for the treatment of onychomycosis. Adv Dermatol Allergology 2015; 1: 40-45

34 Lauharanta J. Comparative efficacy and safety of amorolfine nail lacquer 2\% versus 5\% once weekly. Clin Exp Dermatol 1992; 17: 41 - 43

35 Reinel $D$, Clarke $C$. Comparative efficacy and safety of amorolfine nail lacquer $5 \%$ in onychomycosis, once-weekly versus twice-weekly. Clin Exp Dermatol 1992; 17: 44-49

36 Abrams BB, Hänel H, Hoehler T. Ciclopirox olamine: A hydroxypyridone antifungal agent. Clin Dermatol 1991; 9: 471-477

37 Gupta AK, Skinner AR, Cooper EA. Evaluation of the efficacy of ciclopirox $0.77 \%$ gel in the treatment of tinea pedis interdigitalis (dermatophytosis complex) in a randomized, double-blind, placebo-controlled trial. Int Soc Dermatol 2005; 44: 590-593

38 Gupta AK. Ciclopirox: an overview. Int J Dermatol 2001; 40: 305 -310

39 Subissi A, Monti D, Togni $G$ et al. Ciclopirox Recent Nonclinical and Clinical Data Relevant to its Use as a Topical Antimycotic Agent. Drugs 2010; 70: $2133-2152$

40 Shemer $A$, Nathanson $N$, Trau $H$ et al. Ciclopirox nail lacquer for the treatment of onychomycosis: An open non-comparative study. J Dermatol 2010; 37: 137-139

41 Baran R, Tosti A, Hartmane I et al. An innovative water-soluble biopolymer improves efficacy of ciclopirox nail lacquer in the management of onychomycosis. J Eur Acad Dermatol 2009; 23: 773-781

42 Täuber A, Müller-Goymann CC. In vitro permeation and penetration of ciclopirox olamine from poloxamer 407-based formulations - comparison of isolated human stratum corneum, bovine hoof plates and keratin films. Int J Pharm 2015; 489: 73-82

43 Uchida K, Tanaka T, Yamaguchi H. Achievement of Complete Mycological Cure by Topical Antifungal Agent NND502 in Guinea Pig Model of Tinea Pedis. Microbiol Immunol 2003; 42: 143-146

44 Koga $H$, Nanjoh $Y$, Kaneda $H$ et al. Short-Term Therapy with Luliconazole, a Novel Topical Antifungal Imidazole, in Guinea Pig Models of 
Tinea Corporis and Tinea Pedis. Antimicrob Agents Ch 2012; 56: $3138-3143$

45 Scher RK, Nakamura N, Tavakkol A. Luliconazole: a review of a new antifungal agent for the topical treatment of onychomycosis. Mycoses 2014; 57 : 389-393

46 Vejnovic I, Huonder C, Betz G. Permeation studies of novel terbinafine formulations containing hydrophobins through human nails in vitro. Int J Pharm 2010; 397: $67-76$

47 Elewski BE, Ghannoum MA, Mayser P et al. Efficacy, safety and tolerability of topical terbinafine nail solution in patients with mild-to-moderate toenail onychomycosis: results from three randomized studies using double-blind vehicle-controlled and open-label active-controlled designs. J Eur Acad Dermatol 2013; 27: 287-294
48 Dominicus $R$, Weidner C, Tate $H$ et al. Open-label study of the efficacy and safety of topical treatment with TDT 067 (terbinafine in Transfersome ${ }^{\circledR}$ ) in patients with onychomycosis. Brit J Dermatol 2012; 166: $1360-1362$

49 The United States Pharmacopeial Convention. (725) Topical and Transdermal Drug Products - Product Performance Tests. Pharmacopeial Forum; 2009; 35

50 Nakashima T, Nozawa A, Ito $T$ et al. Experimental tinea unguium model to assess topical antifungal agents using the infected human nail with dermatophyte in vitro. J Infect Chemother 2002; 8: 331-335

51 Lusiana, Reichl S, Müller-Goymann C. Infected nail plate model made of human hair keratin for evaluating the efficacy of different topical antifungal formulations against Trichophyton rubrum in vitro. Eur J Pharm Biopharm 2013; 84: 599-605 